\title{
Etoposide Reduces Peroxynitrite-Induced Cytotoxicity via Direct Scavenging Effect
}

\author{
In-Young Choi and Won-Ki Kim* \\ Department of Neuroscience, Korea University College of Medicine, \\ Seoul 136-705, Korea
}

\begin{abstract}
Previously, we reported that glucose-deprived astrocytes are more vulnerable to the cytotoxicity of peroxynitrite, the reaction product of nitric oxide and superoxide anion. The augmented vulnerability of glucose-deprived astrocytes to peroxynitrite cytotoxicity was dependent on their proliferation rate. Inhibition of cell cycle progression has been shown to inhibit the apoptotic cell death occurring in cerebral ischemia-reperfusion. In the present study, we demonstrate that the increased death of glucose-deprived astrocytes by peroxynitrte was largely blocked by the cell cycle phase G2/M transition blocker etoposide. However, the cytoprotective effect of etoposide was not associated with its inhibition of cell cycle progression. Instead, etoposide effectively scavenged peroxynitrite. However, etoposide did not scavenge individual nitric oxide and superoxide anion and it did not prevent the hydrogen peroxide-induced cytotoxicity. The present results indicate that etoposide prevents the toxicity of peroxynitrite in astrocytes by directly scavenging peroxynitrite, not by inhibiting cell cycle progression.
\end{abstract}

Key words: etoposide, peroxynitrite, glucose deprivation, astrocyte, cell death

\section{INTRODUCTION}

Immunostimulated glial cells simultaneously produce nitric oxide (NO) and superoxide anion $\left(\mathrm{O}_{2}{ }^{-{ }^{-}}\right)$ via expression and activation of inducible nitric oxide (iNOS) (Simmons and Murphy, 1992). NO and $\mathrm{O}_{2}{ }^{-}$rapidly react in a $1: 1$ stoichiometry to form a strong oxidant $\mathrm{ONOO}^{-}$(Beckman et al., 1990). ONOO $^{-}$has been found to play a critical role in tissue injury and appears to mediate many of the cytotoxic effects (Beckman et al., 1990). Previously, we showed that immunostimulated as-

*To whom correspondence should be addressed.

TEL: 82-2-920-6094, FAX: 82-2-953-6095

e-mail: wonki@korea.ac.kr

Received September 12, 2010

Accepted for publication September 27, 2010 trocytes themselves became highly vulnerable to glucose deprivation (GD) (Choi and Kim, 1998; Choi et al., 2001). This enhanced vulnerability was attributed to the accumulation of $\mathrm{ONOO}^{-}$due to the disruption of intracellular antioxidant system (i.e., decreased level of reduced glutathione) in glucose-deprived immunostimulated astrocytes (Choi and Kim, 1998a; 1998b; Choi et al., 2000; 2001). Expectedly, the $\mathrm{ONOO}^{-}$-releasing reagent 3-morpholinosydnonimine (SIN-1) also augmented the death of glucose-deprived astrocytes. Interestingly, we further found that the augmented death of immunostimulated or SIN-1-treated astrocytes under GD was dependent on the proliferative state of the astrocytes (Choi and Kim, 1998b).

Activation of iNOS was reported to induce cytotoxicity in part by disturbing cell cycle progression 
(Gu et al., 2000; Kotamraju et al., 2007). Apoptotic death of some cells can be blocked by coordinating the progression through the cell cycle and/or by preventing the inappropriate activation of cell cycle signalling pathways (Park et al., 1997; Zhu et al., 2007). Because proliferating immunostimulated astrocytes are much more vulnerable to $G D$, it is reasonable to think that the augmented death could be prevented by inhibition of cell cycle progression.

In the present study, therefore, we examined the possible cytoprotective effect of the DNA topoisomerase II inhibitor etoposide on peroxynitrite toxicity in proliferating astrocytes. Interestingly, the present results demonstrates for the first time that etoposide markedly blocks the augmented toxicity of $\mathrm{ONOO}^{-}$in SIN-1-treated/glucose-deprived astrocytes by directly scavenging peroxynitrite, not by inhibiting cell cycle progression.

\section{MATERIALS AND METHODS}

\section{Astrocyte cultures}

Astrocytes were cultured from the prefrontal cortices of 2- to 5-day-old Sprague-Dawley rat pups as previously described (Choi and Kim, 1998a) In brief, cells were dissociated by mild trypsinization (10 min at $37^{\circ} \mathrm{C}$ with Dulbecco's modified Eagle medium (DMEM) containing $0.1 \%$ trypsin) and passed through a sterile nylon sieve (130 $\mu \mathrm{m}$ pore size) into DMEM containing $10 \%$ heat-inactivated fetal bovine serum (FBS). Cells were then plated (about 50,000 cells $/ \mathrm{ml})$ onto poly-L-lysine $(20 \mu \mathrm{g} / \mathrm{ml})$-coated $75-\mathrm{cm}^{2}$ culture bottles and maintained for one week in DMEM/F12 supplemented with $10 \%$ FBS. Astrocytes were then trypsinized, washed and re-plated in the growth medium onto poly-L-lysine $(20 \mu \mathrm{g} /$ $\mathrm{ml}$ )-coated 48-well plates. Cells were used for the experiments 5 to 7 days later.

\section{Measurement of lactate dehydrogenase}

Astrocytic injury and death was assessed by morphological examination of cells using phase-contrast microscopy and quantified by measuring the amount of lactate dehydrogenase (LDH) released into the bathing medium. Activity of LDH was measured using a diagnostic kit (Sigma Chemical Co., St. Louis, MO). In brief, NADH and pyruvate $(0.1 \mathrm{w} / \mathrm{v} \%)$ were added and the samples incubated at $37^{\circ} \mathrm{C}$ for $30 \mathrm{~min}$. The samples then were incubated with the coloring reagent for $20 \mathrm{~min}$. The reaction was stopped by adding $0.4 \mathrm{~N} \mathrm{NaOH}$, and the activity (unit/ml) of LDH in each sample was calculated from the standard curve. Total LDH, which corresponds to complete astrocyte death, was measured in sister cultures frozen and thawed after the experiments. Cell viability was expressed as percentage of total LDH.

\section{Determination of cell cycle distribution}

Cells were washed with phosphate-buffered saline (PBS), trypsinized and pooled with the cells collected from corresponding suspension at the end of treatment. After washing once with PBS, cells were resuspended in citrate buffer $(250 \mathrm{mM}$ sucrose, $40 \mathrm{mM}$ sodium citrate, $\mathrm{pH}$ 7.6). Cells were stained for $30 \mathrm{~min}$ in ice-cold DNA staining/lysis buffer $\left(\mathrm{Mg}^{2+}\right.$ and $\mathrm{Ca}^{2+}$-free PBS containing $10 \mu \mathrm{g} /$ $\mathrm{ml} \mathrm{RNase,} 20 \mu \mathrm{g} / \mathrm{ml}$ propidium iodide, $0.5 \% \mathrm{NP}-40$, $0.5 \mathrm{mM}$ EDTA, pH 7.2). Flow cytometric analysis was performed on a FACS Caliber (Becton Dickinson, Mountain View, $C A$ ) equipped with aircooled $488 \mathrm{~nm}$ argon-ion laser. Using a CELLQuest software (Becton Dickinson, Mountain View, CA), cell cycle distribution was analysed with a minimum of 10,000 cells.

\section{Measurement of $\mathrm{ONOO}^{-}$-induced oxidation of dihydrorhodamine 123}

The $\mathrm{ONOO}^{-}$-dependent oxidation of dihydrorhodamine $123(\mathrm{DHR})$ to rhodamine $123(\mathrm{RH})$ was measured, as described before (Choi et al., 2002). Briefly, SIN-1 $(200 \mu \mathrm{M})$ was added into phosphatebuffered saline solution (PBS) containing DHR (10 $\mu \mathrm{M})$ in the absence and presence of etoposide. After a 10 min incubation at room temperature, the fluorescence of $\mathrm{RH}$ was measured at an excitation wavelength of $485 \mathrm{~nm}$ and emission wavelength of $530 \mathrm{~nm}$ (slit widths 20 and $25 \mathrm{~nm}$, respectively) using a fluorescence microplate reader (FL600, Bio-tek Instruments, Inc., Winooski, VT).

\section{Measurement of NO}

As previously described by us (Choi et al., 2002), the amount of NO was measured with a commercially available Clark-type electrode (ISO-NO, Mark II, World Precision Instruments, Sarasota, FL). 
NO is oxidized on the surface of a prepolarized working electrode, permeable only for gases with low molecular weights, resulting in electrical current. This current $(\mathrm{pA})$ was recorded at $0.5 \mathrm{~Hz}$ and converted to a $\mathrm{nM}$ concentration of $\mathrm{NO}$ using a calibration curve that was generated daily. NO was released from $200 \mu \mathrm{M}$ S-nitroso-N-acetylpenicillamine (SNAP) by incubation in PBS containing 4 $\mathrm{mM}$ cysteine as a reducing agent and various concentrations of etoposide. All reagents were freshly prepared before use. The formation of NO was quantified from the initial rate of release using the data acquisition system Duo18 (World Precision Instruments, Sarasota, FL).

\section{Measurement of superoxide anion}

As previously described by us (Choi et al., 2002), the amount of superoxide anion was monitored with a Berthold LB9505 luminometer (Bad Wildbad, Germany). The reaction mixtures contained $40 \mathrm{mU} / \mathrm{ml}$ xanthine oxidase, $5 \mu \mathrm{M}$ lucigenin, and various concentrations of etoposide in $1 \mathrm{ml}$ of air-saturated PBS ( $\mathrm{pH}$ 10). The superoxide-producing reaction was initiated by adding xanthine to yield a final concentration of $40 \mu \mathrm{M}$. All reagents were freshly prepared in PBS. Chemiluminesence was measured at 1-min intervals for $10 \mathrm{~min}$, and data are expressed as the integrated area under the 10-min curve. Mean blank values obtained by adding 300 $\mathrm{U} / \mathrm{ml} \mathrm{SOD}$ were subtracted from all chemiluminescent measurements.

\section{Measurements of glutathione}

For the measurement of glutathione (GSH), astrocytes were washed with PBS, and then incubated at $37^{\circ} \mathrm{C}$ for $10 \mathrm{~min}$ with $50 \mu \mathrm{M}$ monochlorobimane. Cells were washed with PBS and then lysed with PBS containing $0.2 \%$ Triton X-100. The fluorescence of the monochlorobimane-GSH complex was measured with a fluorescence microplate reader (FL600, Bio-tek Instruments, Inc., Winooski, VT) (excitation wavelength of $400 \mathrm{~nm}$ and emission wavelength of $480 \mathrm{~nm}$ ). The GSH content of the samples was calculated from the standard curve prepared from GSH standards incubated in the presence of monochlorobimane and glutathione transferase (Sigma Chemical Co., St. Louis, MO). The concentration of $\mathrm{GSH}$ was expressed as $\mathrm{nmol} / \mathrm{mg}$ protein; protein content was determined using the bicinchoninic acid (Smith et al., 1985).

\section{Measurement of hydrogen peroxide}

Hydrogen peroxide $\left(\mathrm{H}_{2} \mathrm{O}_{2}\right)$ was measured spectrophotometrically with some modifications at 550 $\mathrm{nm}$ at $37^{\circ} \mathrm{C}$ by the peroxydase-catalysed conversion of 4-aminophenazone to a pink-colored substance. Measurement was started after adding reagent to solution of various concentrations of etoposide and $\mathrm{H}_{2} \mathrm{O}_{2}$. This reagent consisted of 10 parts of solution A [4.2 mM 3,5-dichloro-2-hydroxybenzenesulphonic acid, dissolved in Mops buffer (50 mM Mops/50 mM $\mathrm{KCl}, \mathrm{pH}$ 7.4)], 1 part of solution $\mathrm{B}(33 \mathrm{mM}$ 4-aminophenazone) and 2.3 units $/ \mathrm{ml}$ peroxydase (final activity).

\section{Statistical analysis}

Data are expressed as the mean \pm standard error of mean (S.E.M.) and analysed for statistical significance using ANOVA followed by Scheffe's test for multiple comparison. A $p$ value $<0.05$ was considered significant.

\section{RESULTS}

As we previously reported (Choi and Kim, 1998a; Choi et al., 2002a; 2002b), SIN-1 potentiated the $\mathrm{LDH}$ release (i.e., a cell death marker) in glucose-deprived astrocytes (Fig. 1). Presence of etoposide $(10 \mu \mathrm{M}) 16 \mathrm{~h}$ before (i.e., pre-treatment) and during GD (i.e., co-treatment) completely blocked the potentiated cell death (Fig. 1). Similarly, cotreatment of etoposide alone also blocked the increased cell death. However, FACS analysis using propidium iodide showed that co-treatment of etoposide alone did not arrest the cell cycle progression (Table 1). It implies that the cytoprotective effect of etoposide may not caused by its inhibition of cell cycle progression.

In brain, one of many well-known actions of astrocytes is to produce antioxidants, which scavenge reactive oxygen species and buffer oxidative stress. Astrocytes are known to be the main source of GSH which acts as a free radical scavenger and is important in recycling other antioxidants (Markar et al., 1994; Ju et al., 2000). Thus, astrocytes ap- 


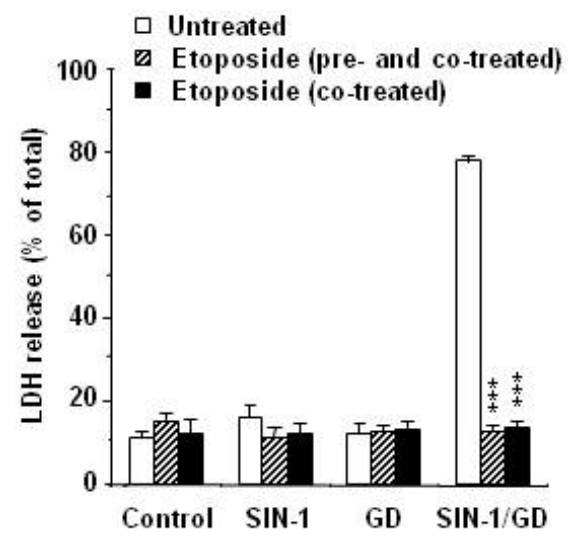

Fig. 1. Etoposide inhibits the increased death in astrocytes simultaneously exposed to $\mathrm{SIN}-1$ and GD. Astrocytes were exposed to $200 \mu \mathrm{M} \mathrm{SIN-1} \mathrm{and/or} \mathrm{GD} \mathrm{with} \mathrm{or} \mathrm{without} \mathrm{pre-} \mathrm{and}$ co-treatment, or just co-treatment of etoposide. LDH levels were determined $6 \mathrm{~h}$ after starting the GD. Data are the percent of total LDH and expressed as the mean S.E.M. $\mathrm{N}=5$. ${ }^{* \star \star} \mathrm{p}<0.001$, (two-way ANOVA followed by post-hoc Scheffe's test) significantly different from the untreated group.

Table 1. Changes of cell cycle distribution by etoposide. Astrocytes were exposed to $200 \mathrm{mM} \mathrm{SIN-1}$ and/or glucose deprivation with or without pre-(16 h) and co-treatment, or just co-treatment of etoposide

\begin{tabular}{lccc}
\hline \multicolumn{1}{c}{ Treatments } & G0+G1 $(\%)$ & $\mathrm{S}(\%)$ & $\mathrm{G} 2+\mathrm{M}(\%)$ \\
\hline Control & $77.6 \pm 0.12$ & $11.8 \pm 1.64$ & $11.8 \pm 0.71$ \\
SIN-1 & $75.3 \pm 1.64$ & $12.2 \pm 0.28$ & $11.9 \pm 1.43$ \\
GD & $78.9 \pm 0.11$ & $11.3 \pm 1.34$ & $9.9 \pm 0.93$ \\
SIN-1+GD & $74.1 \pm 0.59$ & $12.7 \pm 0.96$ & $12.5 \pm 1.55$ \\
SIN-1 + GD +etoposide & $81.4 \pm 2.98^{\star}$ & $14.5 \pm 1.78$ & $4.0 \pm 0.25^{\star \star}$ \\
(pre- and co-treated) & & & \\
SIN-1 + GD +etoposide & $76.8 \pm 2.90$ & $12.1 \pm 1.43$ & $10.9 \pm 1.85$ \\
(co-treated) & & & \\
\hline
\end{tabular}

$\mathrm{N}=7 .{ }^{*} \mathrm{p}<0.05,{ }^{* *} \mathrm{p}<0.001$, compared with the group simultaneously treated with SIN-1 and GD in the absence of etoposide.

pear to be resistant to the actions of the strong oxidant $\mathrm{ONOO}^{-}$(Barker et al., 1996). In the present study, the level of GSH in astrocytes was synergistically reduced by SIN-1 and GD (Fig. 2A). Co-treatment of etoposide prevented the synergistic decrease of GSH (Fig. 2A). Pretreatment of Lbuthionine-S,R-sulfoximine (BSO, a relatively specific inhibitor of $\mathrm{GSH}$ biosynthesis) for $16 \mathrm{~h}$ depleted the intracellular GSH (Fig. 2B). Depletion of GSH itself did not induce the cell death, but increased the release of LDH in astrocytes exposed to SIN-1 or SIN-1/ GD (Fig. 2C). Although etoposide did not block the GSH depletion by BSO, it inhibited the
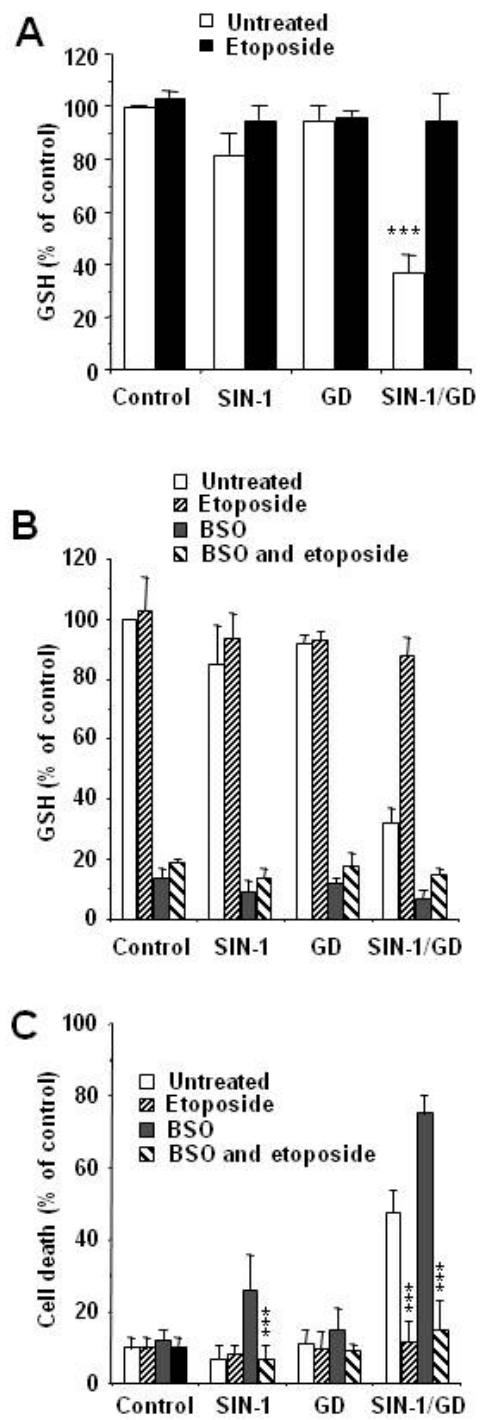

Fig. 2. Etoposide inhibits the depletion of GSH in astrocytes simultaneously exposed to $\mathrm{SIN}-1$ and GD. (A) Astrocytes were exposed to $200 \mu \mathrm{M} \mathrm{SIN-1} \mathrm{and/or} \mathrm{GD} \mathrm{with} \mathrm{or} \mathrm{without} \mathrm{co-treat-}$ ment of etoposide. GSH levels were measured $1 \mathrm{~h}$ after starting GD. Data are the percent of total LDH and expressed as the mean \pm S.E.M. $N=6$. ${ }^{* * *} \mathrm{p}<0.001$, (two-way ANOVA followed by post-hoc Scheffe's test) significantly different from the untreated control group. (B) Astrocytes were preincubated with $100 \mu \mathrm{M}$ L-BSO for $12 \mathrm{~h}$ and then incubated in various conditions. GSH levels were measured $1 \mathrm{~h}$ after starting $\mathrm{GD}$ in the absence and presence of $200 \mu \mathrm{M} \mathrm{SIN}-1$ and/or GD, and $10 \mu \mathrm{M}$ etoposide. (C) $\mathrm{LDH}$ levels were measured $6 \mathrm{~h}$ after starting of $\mathrm{GD}$ in the absence and presence of $200 \mu \mathrm{M} \mathrm{SIN-1}$ and/or GD, and $10 \mu \mathrm{M}$ etoposide. Data are the percent of total LDH and expressed as the mean \pm S.E.M. $N=9$. ${ }^{* \star *} p<0.001$, (two-way ANOVA followed by post-hoc Scheffe's test) significantly different from the untreated group.

increased peroxynitrite toxicity by BSO (Fig. 2C).

The $\mathrm{ONOO}^{-}$plays a critical role in the enhanced vulnerability of astrocytes to GD (Ju et al., 2000; 
A
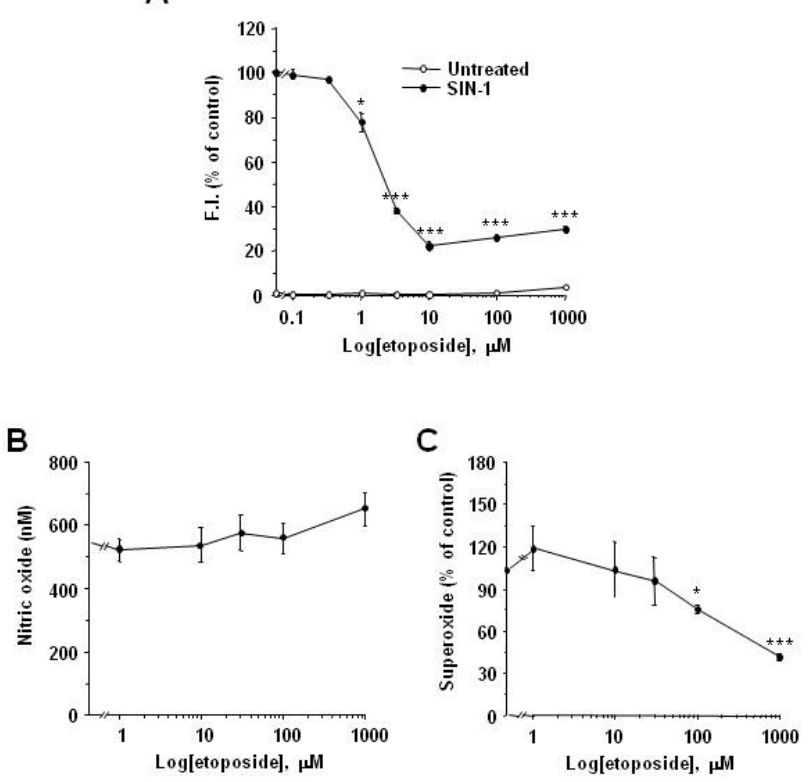

Fig. 3. Etoposide scavenges peroxynitrite, but not $\mathrm{NO}$ and superoxide anion. (A) Peroxynitrite. Cells were loaded with DHR and then the fluorescence intensities were measured in the presence and absence of $\mathrm{SIN}-1$ and/or etoposide. Data are expressed as fluorescence intensities (F.I.). (B) Nitric oxide. NO was generated from SNAP in the presence of various concentrations of etoposide ( 0.1 to $1 \mathrm{mM})$ and $4 \mathrm{mM}$ cysteine as a reducing agent. The formation of NO was quantified from the initial rate of release using the data acquisition system Duo-18. (C) Superoxide anion. Production of $\mathrm{O}_{2}{ }^{--}$was initiated by adding xanthine (final concentration, $40 \mu \mathrm{M}$ ) to the reaction mixtures described in the Materials and Methods section. Superoxide anion was generated in the presence of various concentration of etoposide $(0.1$ to $1 \mathrm{mM})$. All data were normalized by the mean blank values obtained by adding $300 \mathrm{U} / \mathrm{ml}$ SOD. Results were expressed mean \pm S.E.M. from 4 independent experiments. * $p$ $<0.05,{ }^{* * *} p<0.001$, (two-way ANOVA followed by post-hoc Scheffe's test) significantly different from the value obtained in the absence of etoposide.

Choi et al., 2002a; 2002b). To quantify the $\mathrm{ONOO}^{-}$ scavenging effect of etoposide, we used the dihydrorhodamine 123 . We found that etoposide effectively inhibited $\mathrm{ONOO}^{-}$(SIN-1)-induced oxidation of dihydrorhodamine 123 to rhodamine 123 in the presence of catalase (Fig. 3A). However, etoposide was little or less efficacious in scavenging NO (Fig. 3B) and $\mathrm{O}_{2}^{-{ }^{-}}$(Fig. 3C).

Previously, we reported that GD increased the intracellular concentration of $\mathrm{H}_{2} \mathrm{O}_{2}$ in immunostimulated astrocytes, leading to astroglial cell death (Choi et al., 2004). Our present study showed that both GSH depletion and death in astrocytes simultaneously exposed to $\mathrm{GD}$ and $\mathrm{H}_{2} \mathrm{O}_{2}$ were not
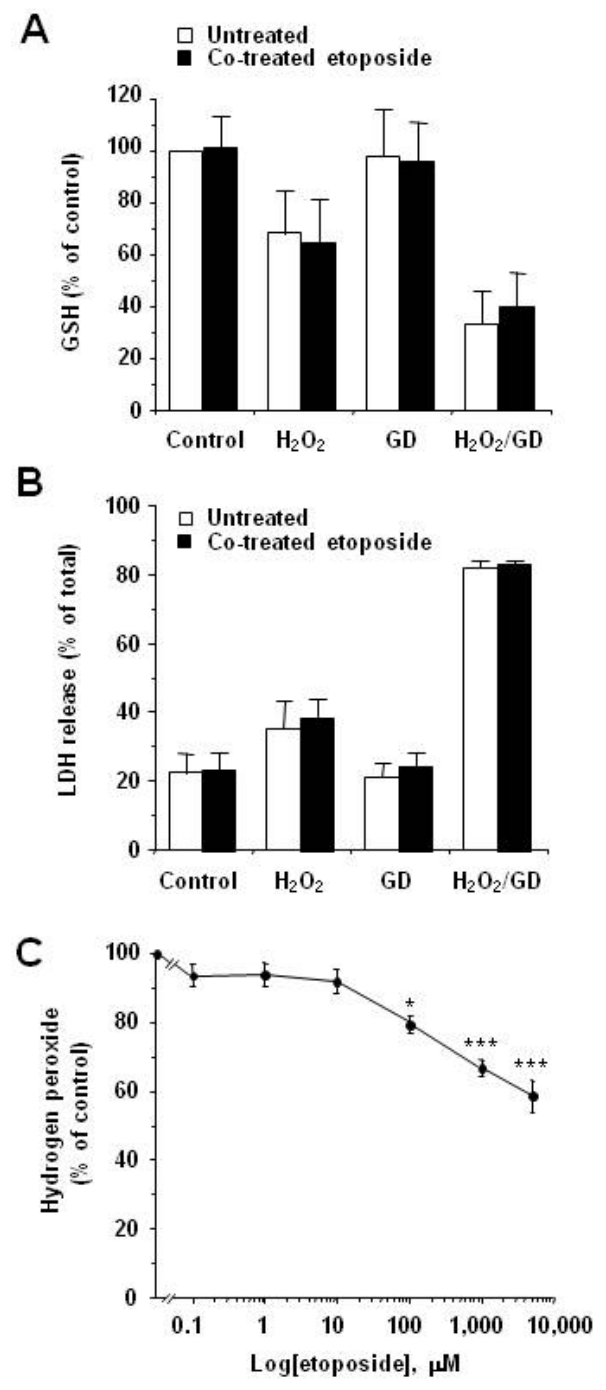

Fig. 4. (A) Etoposide does not inhibit the depletion of GSH in $\mathrm{H}_{2} \mathrm{O}_{2}$-treated astrocytes. Cells were exposed to $\mathrm{H}_{2} \mathrm{O}_{2}(100 \mu \mathrm{M})$ and $\mathrm{GD}$ in the absence and presence of etoposide. GSH levels were measured at $30 \mathrm{~min}$ after starting $\mathrm{GD}$ in the absence and presence of $100 \mu \mathrm{M} \mathrm{H}_{2} \mathrm{O}_{2}$. Data are expressed as the percent of untreated astrocytes. $\mathrm{N}=7$. (B) Etoposide does not prevent the potentiated $\mathrm{H}_{2} \mathrm{O}_{2}$ toxicity in glucose-deprived astrocytes. Astrocytes were exposed to $\mathrm{H}_{2} \mathrm{O}_{2}(100 \mu \mathrm{M})$ and $\mathrm{GD}$ in the absence and presence of etoposide for $2 \mathrm{~h}$ and then incubated in the culture medium. LDH levels were determined $6 \mathrm{~h}$ after starting GD. Data are the percent of total LDH and expressed as the mean \pm S.E.M. $\mathrm{N}=6$. (C) Scavenging effect of etoposide on $\mathrm{H}_{2} \mathrm{O}_{2}$. Various concentrations of etoposide were incubated with $\mathrm{H}_{2} \mathrm{O}_{2}$ $(100 \mu \mathrm{M})$ for $15 \mathrm{~min}$ at room temperature. The amounts of $\mathrm{H}_{2} \mathrm{O}_{2}$ were spectrophotometrically measured at $550 \mathrm{~nm}$. Data are expressed as the percent of control. $\mathrm{N}=5$. ${ }^{*} \mathrm{p}<0.05,{ }^{* \star *} \mathrm{p}<0.001$, (two-way ANOVA followed by post-hoc Scheffe's test) significantly different from the value obtained in the absence of etoposide.

reversed by etoposide (Fig. 4A, B, respecively). We further found that etoposide did not effectively scavenge $\mathrm{H}_{2} \mathrm{O}_{2}$ (Fig. $4 \mathrm{C}$ ). 


\section{DISCUSSION}

Many researchers have used etoposide for experimentally inducing apoptosis in tumor cells. Studies on etoposide-induced apoptotic cell death include the processing of stabilized cleavage complexes into frank DNA strand breaks, sensing of the DNA damage, leading to activation of stress-asociated signaling pathways and cell cycle arrest (Kubota et al., 1990; Ryan et al., 1991; Tsao et al., 1992). Etoposide can also activate a pre-existing group of enzymes and enzyme precursors, typified by the cysteine-dependent aspartate-directed protease (caspases) (Henderson et al., 2005). The present study, however, demonstrates that the anti-tumoric DNA topoisomerase II inhibitor etoposide can reduce the peroxynitrite toxicity in glucose-deprived astrocytes by directly scavenging peroxynitrite, not by inhibiting cell cycle progression. Furtherore, etoposide interacts with $\mathrm{ONOO}^{-}$most likely due to the high reactivity of $\mathrm{ONOO}^{-}$, but not with other products $\mathrm{NO}, \mathrm{O}_{2}{ }^{-}$and $\mathrm{H}_{2} \mathrm{O}_{2}$.

The mammalian cell cycle maintains internal checkpoints at which cells are arrested when previous events have not been completed in response to external signals (Hartwell and Weinert, 1989). The cell cycle checkpoints are thought to exist at the $\mathrm{G} 1 / \mathrm{S}$ and G2/M transitions (Agarwal et al., 1995). Etoposide has been used as a potent and reversible blocker of the cell cycle that appears to act at the G2/M transition. Previously, we found that the $\mathrm{G} 1 / \mathrm{S}$ transition blockers mimosine and ciclopirox also blocked the peroxynitrite toxicity. Like etoposide, mimosine reduced the augmented death of glucose-deprived immunostimulated astrocytes by directly scavenging peroxynitrite rather than suppressing the cell cycle progression (Choi et al., 2002a). Unlike mimosine, however, ciclopirox blocked the peroxynitrite toxicity in glucose-deprived SIN-1-treated astrocytes by attenuating peroxynitrite-induced mitochondrial dysfunction, not by scavenging peroxynitrite (Choi et al., 2002b; Lee et al., 2005). Ciclopirox neither prevented the depletion of reduced glutathione in glucose-deprived SIN-1-treated astrocytes, nor scavenged oxidants such as peroxynitrite, nitric oxide, superoxide anion, hydrogen peroxide and hydroxyl radical (Choi et al., $2002 \mathrm{~b}$ ). Because of those various mechanisms of action, therefore, such cell cycle inhibitors should be carefully selected for the studies on oxidative stress-related cell deaths.

\section{ACKNOWLEDGEMENTS}

This work was supported by a grant (\#2009K001250) from Brain Research Center of the 21st Century Frontier Research Program funded by the Ministry of Science and Technology.

\section{REFERENCES}

Agarwal ML, Agarwal A, Tatlor WR and Stark GR (1995) P53 controls both the G2/M and $\mathrm{G} 1$ cell cycle checkpoints and mediates reversible growth arrest in human fibroblasts. Pro Nat'l Acad Sci (USA) 92:8493-8497.

Barker JE, Bolanos JP, Land JM, Clark JB and Heales SJ (1996) Glutathione protects astrocytes from peroxynitritemediated mitochondrial damage: implications for neuronal/astrocytic trafficking and neurodegeneration. Develop Neurosci 18:391-396.

Beckman JS, Beckman TW, Chen J and Marshall PA (1990) Freeman, BA. Apparent hydroxyl radical production by $\mathrm{ONOO}^{-}$: implications for endothelial injury from nitric oxide and superoxide. Proc Nat'l Acad Sci (USA) 87: 1620-1624.

Choi IY, Lee SJ, Ju C, Kim HC, Ko KH, Nam W and Kim WK (2000) Protection by a manganese porphyrin of endogenous peroxynitrite-induced death of astrocytes via inhibition of mitochondrial transmembrane potential decrease. Glia 31:155-164.

Choi IY, Lee SJ, Nam W, Park JS, Ko KH, Kim HC, Chung JH, Noh SK, Choi CR, Shin DH and Kim WK (2001) Augmented death in immunostimulated astrocytes deprived of glucose: inhibition by an iron porphyrin FeTMPyP. $J$ Neuroimmunol 112:55-62.

Choi JJ and Kim WK (1998a) Potentiated glucose-deprivation-induced death of astrocytes after induction of iNOS. $J$ Neurosci Res 54:870-875.

Choi JJ and Kim WK (1998b) Proliferation-dependent vulnerability of glucose-deprived astrocytes to nitric oxide-induced cytotoxicity. Neurosci Lett 256:109-112.

Choi JJ, Kong MY, Lee SJ, Kim HC, Ko KH and Kim WK (2002) Ciclopirox prevents peroxynitrite toxicity in astrocytes by maintaining their mitochondrial function: a novel mechanism for cytoprotection by ciclopirox. Neuropharmacology 43:408-417.

Choi JJ, Oh YK, Kim HS, Kim HC, Ko KH and Kim WK (2002) Mimosine prevents the death of glucose-deprived immunostimulated astrocytes by scavenging peroxynitrite. Glia 39:37-46.

Choi JW, Shin CY, Yoo BK, Choi MS, Lee WJ, Han BH, Kim WK, Kim HC and Ko KH (2004) Glucose deprivation increases hydrogen peroxide level in immunostimulated rat primary astrocytes. J Neurosci Res 75:722-731.

Gu M, Lynch J and Brecher P (2000) Nitric oxide increases p21(Waf1/Cip1) expression by a cGMP-dependent pathway 
that includes activation of extracellular signal-regulated kinase and p70(S6k). J Biol Chem 275:11389-11396.

Hartwell LH and Weinert TA (1989) Checkpoints: controls that ensure the order of cell cycle events. Science 246:629634.

Henderson CJ, Aleo E, Fontanini A, Maestro R, Paroni G and Brancolini C (2005) Caspase activation and apoptosis in response to proteasome inhibitors. Cell Death Differ 12: 1240-1254.

Ju C, Yoon KN, Oh YK, Kim HC, Shin CY, Ryu JR, Ko KH and Kim WK (2000) Synergistic depletion of astrocytic glutathione by glucose deprivation and peroxynitrite: correlation with mitochondrial dysfunction and subsequent cell death. J Neurochem 74:1989-1998.

Kotamraju S, Williams CL and Kalyanaraman B (2007) Statininduced breast cancer cell death: role of inducible nitric oxide and arginase-dependent pathways. Cancer Res 67: 7386-7394.

Kubota M, Tanizawa A, Hashimoto H, Shimizu T, Takimoto T, Kitoh T, Akiyama $Y$ and Mikawa $H$ (1990) Cell type dependent activation of poly (ADP-ribose) synthesis following treatment with etoposide. Leukemia Res 14:371375 .

Lee SJ, Jin Y, Yoon HY, Choi BO, Kim HC, Oh YK, Kim HS and Kim WK (2005) Ciclopirox Protects Mitochondria from
Hydrogen Peroxide Toxicity. Br J Pharmacol 145: 469-476. Makar TK, Nedergaard M, Preuss A, Gelbard AS, Perumal AS and Cooper AJ (1994) Vitamin E, ascorbate, glutathione, glutathione disulfide, and enzymes of glutathione metabolism in cultures of chick astrocytes and neurons: evidence that astrocytes play an important role in antioxidative processes in the brain. J Neurochem 62:45-53.

Park DS, Morris EJ, Greene LA and Geller HM (1997) G1/S cell cycle blockers and inhibitors of cyclin-dependent kinases supress camptothecin induced neuronal apoptosis. J Neurosci 17:1256-1270.

Ryan AJ, Squires S, Strutt HL and Johnson RT (1991) Camptothecin cytotoxicity in mammalian cells is associated with the induction of persistent double strand breaks in replicating DNA. Nucleic Acids Res 19:3295-3300.

Simmons ML and Murphy S (1992) Induction of nitric oxide synthase in glial cells. J Neurochem 59:897-905.

Tsao YP, D'Arpa P and Liu L (1992) The involvement of active DNA synthesis in camptothecin-induced $\mathrm{G} 2$ arrest: altered regulation of $\mathrm{p} 34 \mathrm{cdc} 2 / \mathrm{cyclin}$ B. Cancer Res 52: 1823-1829.

Zhu Z, Zhang Q, Yu Z, Zhang L, Tian D, Zhu S, Bu B, Xie $M$ and Wang W (2007) Inhibiting cell cycle progression reduces reactive astrogliosis initiated by scratch injury in vitro and by cerebral ischemia in vivo. Glia 55:546-558. 